\section{L-1,4-CYCLOHEXADIENE-1-ALANINE, AN ANTIMETABOLITE OF L-PHENYLALANINE PRODUCED BY A PSEUDOMONAS}

\author{
Norimasa Onishi, Toshiniko Watanabe, \\ KaZUO IZAKI and HaJIME TAKaHASHI \\ Department of Agricultural Chemistry, \\ Faculty of Agriculture, Tohoku University, \\ Sendai 980, Japan
}

(Received for publication March 31, 1982)

L-1,4-Cyclohexadiene-1-alanine, an antimetabolite of L-phenylalanine, was isolated from the culture broth of a bacterium belonging to the genus Pseudomonas. Although this antimetabolite has been already isolated from culture broths of several species of Streptomycetes, ${ }^{1,2,3)}$ its production by bacteria has not been reported, thus far.

The L-1,4-cyclohexadiene-1-alanine producing organism, designated Pseudomonas sp. strain I30 , was isolated from a soil sample collected in Matsuo Mura, Iwate, Japan. Strain I-30 was found to belong to the genus Pseudomonas from the following taxonomical characteristics: rod with rounded end, $0.6 \times 2.0 \sim 3.0 \mu \mathrm{m}$ in size, motile by polar flagella, Gram-negative, oxidative but not fermentative, catalase positive, oxidase positive, reduces nitrate and easily grows in synthetic media. An electronmicrograph of strain I-30 is shown in Fig. 1.

The strain I-30 produces a strong growth inhibitory substance against Neurospora crassa, when this bacterium was grown in a modified Czapeck-Dox medium containing 3\% sucrose, $0.2 \% \mathrm{NaNO}_{3}, 0.1 \% \mathrm{~K}_{2} \mathrm{HPO}_{4}, 0.05 \% \mathrm{KCl}, 0.05 \%$

Fig. 1. Electronmicrograph of the strain I-30 (Bar indicates $1 \mu \mathrm{m})$.

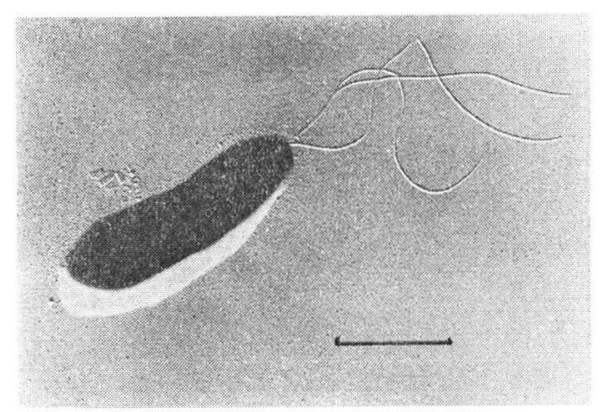

$\mathrm{MgSO}_{4} \cdot 7 \mathrm{H}_{2} \mathrm{O}, 0.001 \% \mathrm{FeSO}_{4} \cdot 7 \mathrm{H}_{2} \mathrm{O}, \mathrm{pH} \quad 7.0$. This substance was purified by a modified method of YAMASHITA et al. ${ }^{1)}$ The culture broth was centrifuged (10 minutes, $10,000 \times g$ ), and the active principle in the supernatant was adsorbed to an anion-exchange resin (Amberlite IRA-45, $\mathrm{OH}^{-}$ form) at $\mathrm{pH} 4.5$ and eluted with $50 \%$ aqueous acetone. The eluate was concentrated in vacuo, spotted on a filter paper (Toyo Roshi No. 527 $40 \times 40 \mathrm{~cm}$ ), and was subjected to ascending paper chromatography with water saturated $n$ butanol. After the paper was dried, the active fraction ( $\mathrm{Rf} 0.50 \sim 0.63$ ) was cut off and eluted with water and the eluate was concentrated in vacuo to dryness. The dried sample was then dissolved in a small amount of water saturated $n$-butanol and centrifuged ( 5 minutes, $400 \times g$ ) to remove the insoluble material. The supernatant was kept at $20^{\circ} \mathrm{C}$ for several days to yield crystals. Recrystallization from water saturated $n$-butanol resulted in colorless crystals.

Elemental analysis of the compound; Found: C 64.36, H 7.79, N 8.32. Anal. Calcd. for $\mathrm{C}_{9} \mathrm{H}_{13} \mathrm{NO}_{2}: \mathrm{C} 64.70, \mathrm{H} 7.84, \mathrm{~N}$ 8.38. The mass spectrum with peaks at $m / z 167,93,74$, contained the molecular ion $m / z 167$, and $\mathrm{M}-74$ (loss of $\mathrm{H}_{2} \mathrm{NCHCOOH}$ ). The ${ }^{1} \mathrm{H}$ NMR and ${ }^{13} \mathrm{C}$ NMR spectra $\left(\mathrm{D}_{2} \mathrm{O}\right.$, DSS $)$ are shown in Figs. 2 and 3, respectively. In Fig. 2 there are three olefinic protons, $\delta 5.77$ (s 2) and $\delta 5.69$ (s 1), and six allylic protons, $\delta 2.67$. In Fig. 3 there are

Fig. 2. ${ }^{1} \mathrm{H}$ NMR spectrum of the substance in $\mathrm{D}_{2} \mathrm{O}$ at $100 \mathrm{MHz}$.

DSS: 3-(Trimethylsilyl)propanesulfonic acid, sodium salt. $\left(\mathrm{C}_{6} \mathrm{H}_{15} \mathrm{NaSSiO}_{3}\right)$.

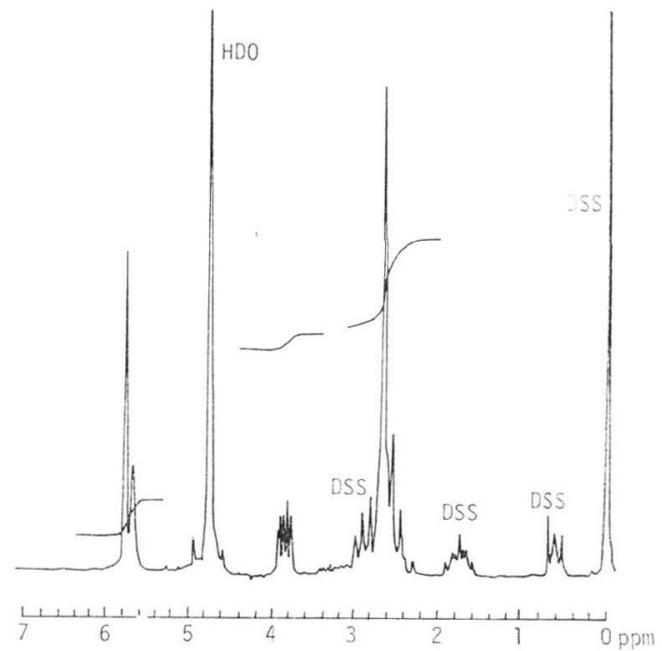


Fig. 3. ${ }^{13} \mathrm{C}$ NMR spectrum of the substance in $\mathrm{D}_{2} \mathrm{O}$.

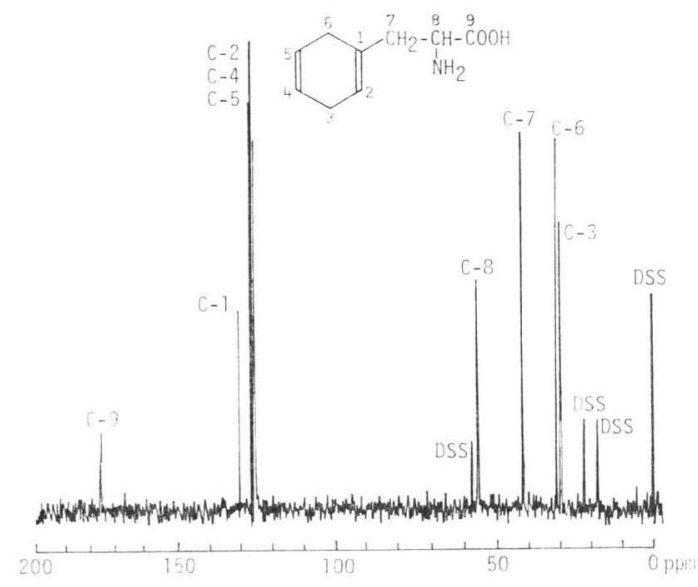

nine carbons (signals $\delta 28.8,30.2,41.3,55.2$, $126.8,127.0,127.3,131.9$ and 177.3). No ultraviolet absorption was seen at wave length higher than $230 \mathrm{~nm}$. L-Amino acid oxidase can abolish the antibiotic activity of this substance but D-amino acid oxidase can not. From these results, this substance was concluded to be L1,4-cyclohexadiene-1-alanine.

This compound, L-1,4-cyclohexadiene-1-alanine, inhibited the growth of Neurospora crassa on Czapeck-Dox agar at lower concentrations than $10 \mu \mathrm{g} / \mathrm{ml}$ (paper disc and dilution methods were used), but the growth inhibition was relieved by the addition of L-phenylalanine to the medium. This compound is positive in ninhydrin reaction (brick orange) and is not stable in the solid state, and is partially converted to L-phenylalanine on exposure to the air. When each of the aromatic amino acids such as
L-Phe, L-Tyr, L-Trp or phenylpyruvate (each $1 \mathrm{mg} / \mathrm{ml}$ ) was added to the culture medium, the strain I-30 did not produce this compound while addition of other amino acids, L-Ala or L-Arg, did not inhibit its production at concentrations higher than $10 \mathrm{mg} / \mathrm{ml}$. These results suggest that L-1,4-cyclohexadiene-1-alanine is synthesized through the route of aromatic amino acids pathway and a feed-back regulation operates in the synthesis of this compound. In this respect, the mechanism of accumulation of this antimetabolite $(100 \mathrm{mg} /$ liter in culture broth at 48 hours) under feed-back regulation seems to be interesting.

\section{Acknowledgements}

We wish to thank Dr. T. Sugryama, of this faculty, for his helpful suggestions during the measurement of the ${ }^{1} \mathrm{H}$ NMR and ${ }^{13} \mathrm{C}$ NMR spectra.

\section{References}

1) Yamashita, T.; N. Miyairi, K. Kunugita, K. Shimizu \& H. SAKAI: L-1,4-Cyclohexadiene1-alanine, an antagonist of phenylalanine, from Streptomyces. J. Antibiotics 23: $537 \sim 541,1970$

2) Scannell, J. P.; D. L. Pruess, T. C. Demny, T. Williams \& A. Stempel: L-3-(2,5-Dihydrophenyl)alanine, an antimetabolite of Lphenylalanine produced by a Streptomycete. J. Antibiotics 23: 618 619, 1970

3) Fickenscher, U.; W. Keller-Schierlein \& H. ZÄHNER: Stoffwechselprodukte von Mikroorganismen. 87. L-2,5-Dihydrophenylalanin. Arch. Mikrobiol. 75: 346 352, 1971 